\title{
ATP-MODELS Language to Represent Domestic Refrigerators Performance with Power Quality Disturbances
}

\author{
I. A. Bacca ${ }^{1}$, M. V. B. Mendonça ${ }^{1}$, C. E. Tavares ${ }^{1}$, I. N. Gondim ${ }^{1}$ and J. C. Oliveira ${ }^{1}$ \\ ${ }^{1}$ Faculty of Electrical Engineering \\ UFU, Federal University of Uberlândia \\ Campus Santa Mônica - Av. João Naves de Ávila, 2121 - Bloco 3N - Uberlândia (Brazil) \\ Phone/Fax number: +55 343239 4733/+55 343239 4704, e-mail: ivandroene@gmail.com, borgesmarcus@yahoo.com.br, \\ carlosetavares@yahoo.com.br, nig_eng@yahoo.com.br, jcoliveira@ufu.br
}

\begin{abstract}
This paper is focused on the subject of computational modelling, experimental validation and performance analysis of refrigerators submitted to nonideal supply conditions. The model uses the time domain approach and the expressions are implemented in the ATP-MODELS platform. Concomitantly to the theoretical work, laboratory procedures have been executed in order to validate the proposal. The results described are useful to highlight the model applicability at investigating the relationship between distinct nonideal supply conditions and the equipment response. The method finds application when considering the area of refunding request of damage in household devices facing anomalies in the distribution system.
\end{abstract}

\section{Key words}

ATP-MODELS, modelling, single-phase motor, power quality, refrigerator.

\section{Introduction}

In recent years, the electrical supply has presented a variety of disturbances that can compromise the normal operation of consumer devices. This situation may jeopardize the residential, commercial and industrial equipment performance and the final result can be understood as serious affects upon the physical appliance integrity. This is especially true for new devices using sophisticated electronic technologies which are generally more sensitive to the power quality [1], [2], [3].

In order to evaluate the equipment performance supplied by electrical network under non-ideal conditions, the present work aims at describing a mathematical modelling and the computational implementation of one of the most common devices in residential and commercial electric installation, i.e. the refrigerator. These products are constructively robust and are characterized by several electrical and protection components, being the single-phase motor the most important element. Therefore, a good representation of this machine is essential to obtain an accurate model to investigate its performance under electrical power supply disturbances [4], [5].

Within this context, this paper focuses the following topics: discussions and development of a computational model to represent commercial refrigerators submitted to ideal and non-ideal voltage conditions; a strategy to represent this load in the ATP platform throughout the well known MODELS language; the validation of the model throughout laboratory experiments and corresponding computational results; the investigation of the refrigerator performance when the supply contains specific disturbances (voltage dip, voltage swell and interruptions) [6], [7].

\section{Domestic Refrigerator Modelling}

To achieve the computational model to represent the refrigerator, the following steps were taken:

\section{A. Characterisation of the Investigated Device}

The main electric component in the refrigerator is its hermetic compressor, which is composed by a singlephase induction machine built up within a metallic carcass. The function of this element is to act as a pump for the refrigeration cycle and provides the transport of the cooling gas as well as it allows for the existence of the high and low pressure areas within this cycle. The Fig. 1 shows a commercial hermetic compressor [8].

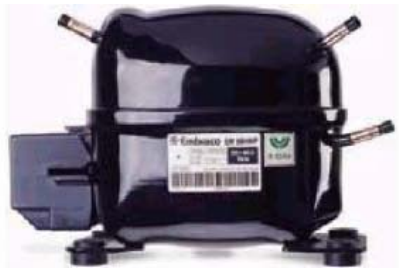

Fig. 1 - Hermetic compressor used in domestic refrigerators. 
Regarding the several commercial types of single-phase induction machine manufactured to the refrigeration industry, the major difference consists in procedures utilized to obtain the starting mechanical torque. In this paper a very common industrial product, identified as THC1340YS compressor has been utilized for the investigations. This product is constituted by a main and an auxiliary winding that only acts at the refrigerator starting conditions. The auxiliary winding has higher resistance and lower value of reactance than the main winding [9], [10].

The Fig. 2 shows the electric motor diagram, witch correspond to the commercial PTCSIR device. After its starting, the auxiliary winding is removed from the system by a PTC (Positive Temperature Coefficient) relay connected in series with it. The PTC relay utilizes a non-linear resistor which depends on the local temperature, that is, the resistance increases quickly when the temperature goes up. Consequently, the current through the auxiliary winding is decreased to almost a null value [11].

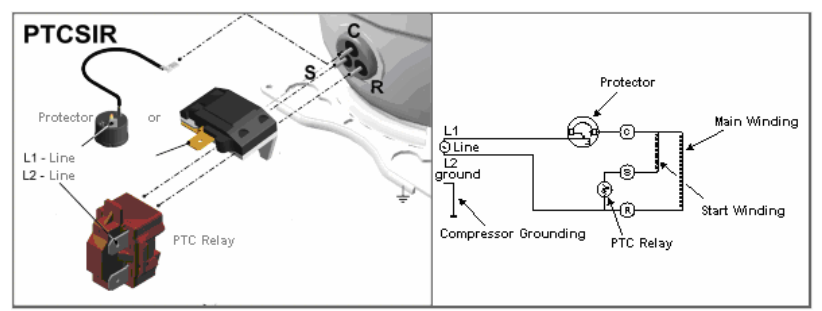

Fig. 2 - Electric motor diagram type PTCSIR.

\section{B. Mathematical Modelling}

The mathematical representation for the analysed motor can be derived from the equivalent asymmetrical ideal induction machine of two poles [12], [13] indicated in Fig. 3.

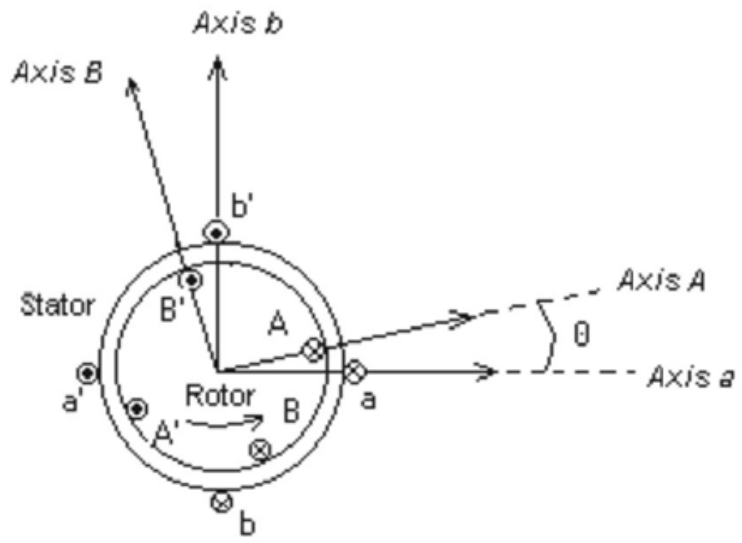

Fig. 3. Representation of the single-phase induction machine.

As it can be seen, the machine is constituted by two stator windings, $a$ and $b$, displaced by $90^{\circ}$ in the space with distinct constructive and electrical characteristics. The rotor is represented by two identical windings ( $A$ and $B$ ), also displaced by $90^{\circ}$ in the space.
Using basic equations applied to electrical machines, the following time domain expressions for the stator and rotor voltages can be derived:

$$
\begin{aligned}
& v_{a}=r_{a} i_{a}+\frac{d \lambda_{a}}{d t} \\
& v_{b}=r_{b} i_{b}+\frac{d \lambda_{b}}{d t} \\
& v_{A}=r_{A} i_{A}+\frac{d \lambda_{A}}{d t} \\
& v_{B}=r_{B} i_{B}+\frac{d \lambda_{B}}{d t}
\end{aligned}
$$

Where:

$v$ are general winding terminal voltages;

$i$ are general winding currents;

$r$ are general winding resistances;

$\lambda$ are general fluxes;

$a$ and $b$ denote stator parameters;

$A$ and $B$ denote rotor parameters;

Complementary, the instantaneous electromagnetic torque $T$ can be obtained through (5).

$$
T=\frac{p}{2} \sum_{i} \sum_{j} i_{i} i_{j} \frac{d L_{i j}}{d \theta}
$$

Where:

$p$ is the pole number;

$i$ are the winding currents;

$i, j$ can be $a, b, A, B$ references;

$L$ are the winding inductances;

$\theta$ is the displacement angle;

\section{Model implementation in the ATP-MODELS}

The instructions used to insert the motor representation in the MODELS language, are:

- INPUT - Indicates input element

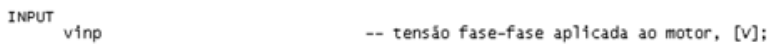

This instruction allows to apply an external electrical voltage to the motor modelling.

- DATA - Informations required by the motor:

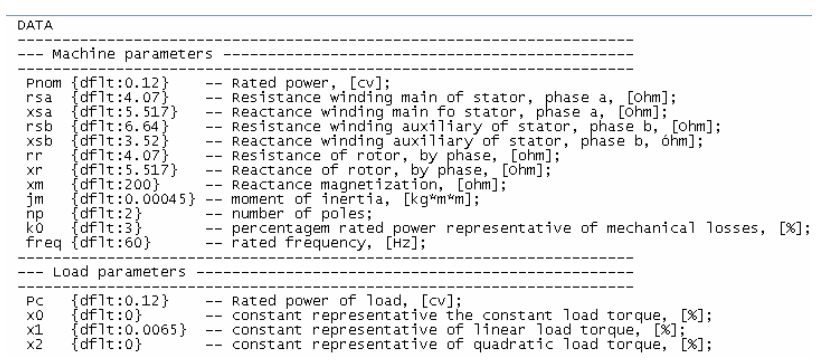


The electrical and mechanical motor equivalent parameters as well as the mechanical information about the machine loading are supplied to the model throughout the above instructions. These data can be obtained by experimental tests or manufacturer datasheet. The mechanical load information can be estimated by considering the thermodynamic fluid refrigerant behavior.

In relation to the variables involved in the calculations and to be available to describe the overall device behavior from the starting instant to the final steady state operation, they are describe in the variable declaration given below.

- VAR - Operational variables and associated parameters :

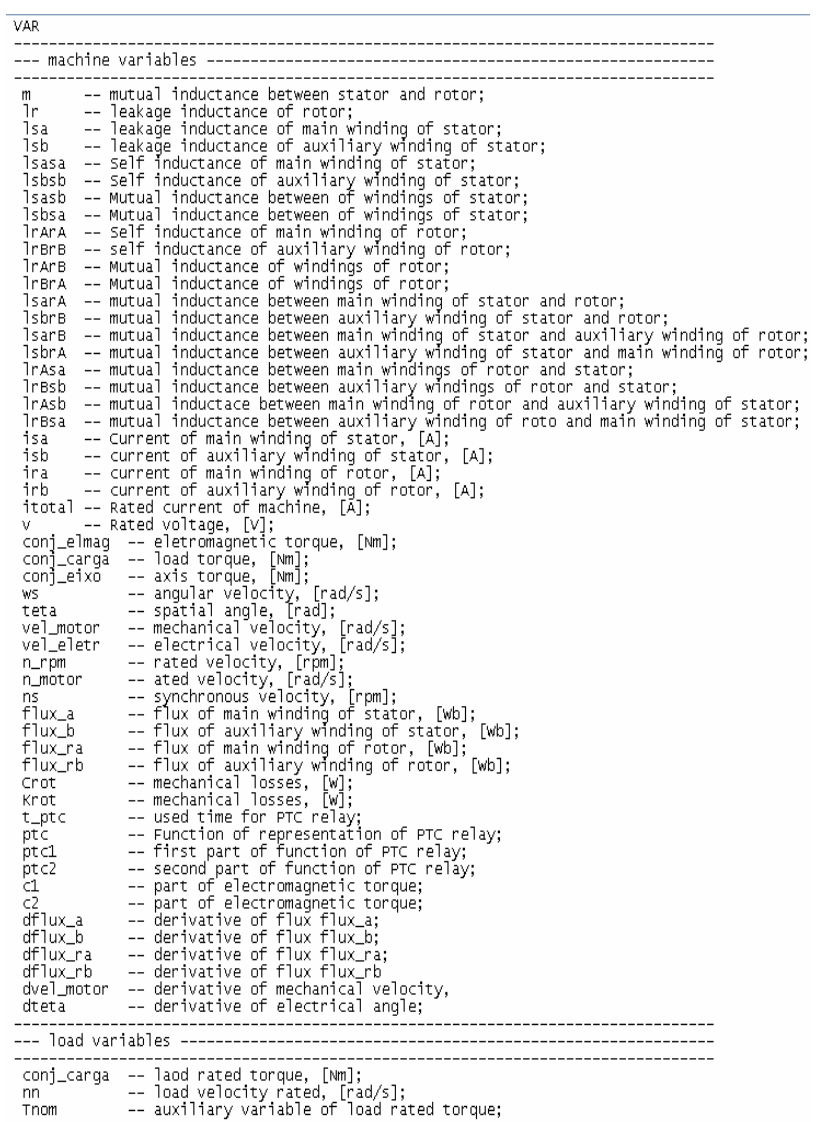

The initial conditions to the above quantities are described as follows. For this specific application the motor was taken as initially disconnected from the supply. Therefore, the initial conditions are nulls.

- INIT - Initial conditions variables:

$$
\begin{aligned}
& \text { INIT } \\
& \text { t_ptc: }:=0 \\
& \text { jsa }:=0 \\
& j \leq b:=0 \\
& \text { jra }:=0 \\
& \text { irb }:=0 \\
& \text { teta }:=0 \\
& \text { norpm }:=0 \\
& \text { itota }:=0 \\
& \text { vel_eletr }:=0 \\
& \text { vel_motar }:=0 \\
& \text { ENDINIT }
\end{aligned}
$$

The next step consists in the device implementation in the ATP itself. This is made by representative equations inserted in the mentioned software throughout the MODELS language. As the expressions do not represent a linear system, it becomes necessary to use a special feature of the MODELS to deal with non-linear equation solution. This uses the Newton-Raphson method through the internal command COMBINE ITERATE.

- EXEC - Model accomplishment:

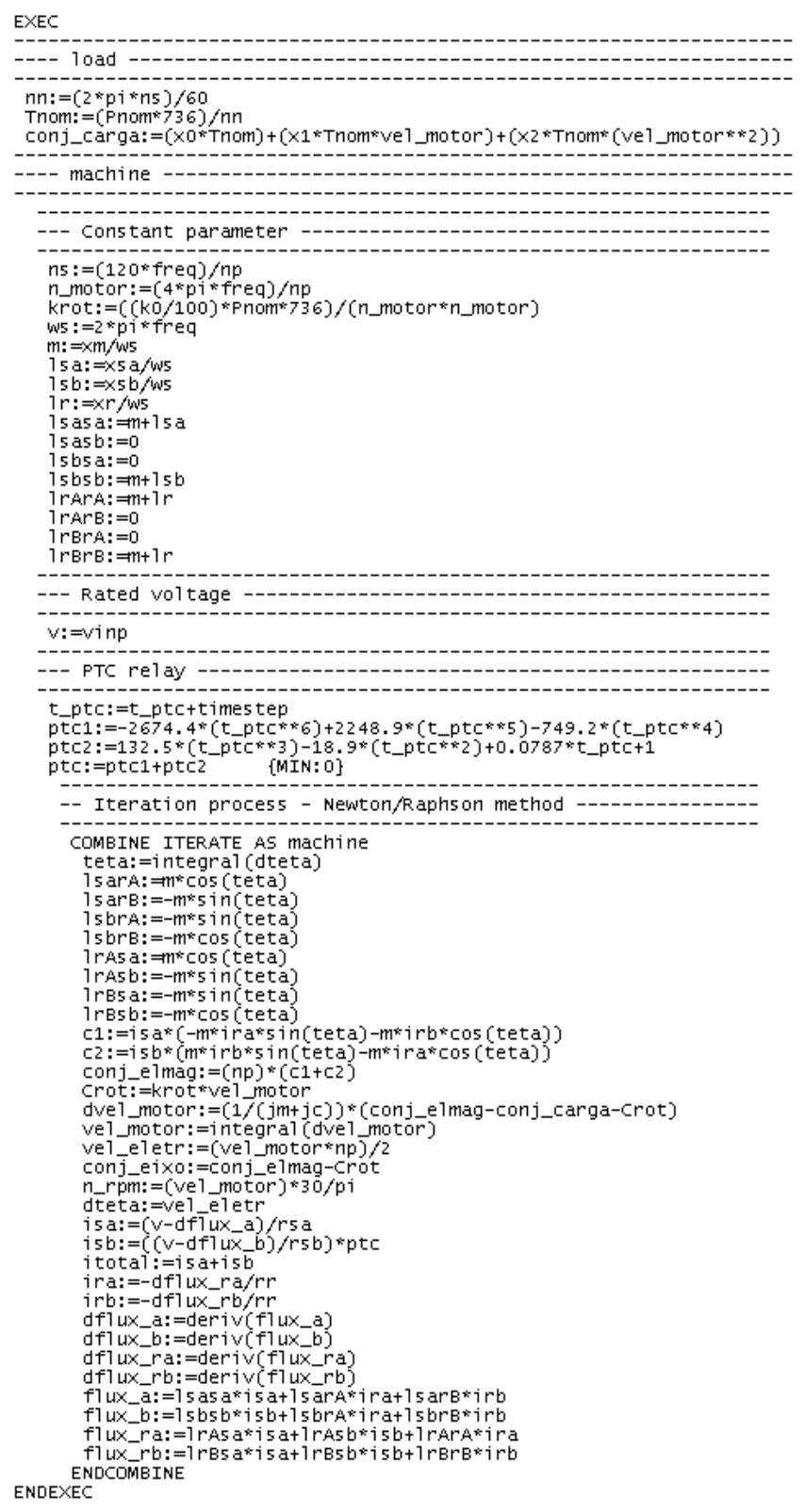

The final product is then represented by an equivalent icon now available in the ATP library. This simple representation has behind its sketch the overall programs here described to investigate the refrigerator device using time domain techniques. This is illustrated in Fig. 4. 


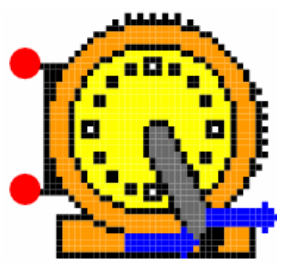

Fig. 4 - Icon representing the refrigerator system into ATPDraw.

\section{Performance Analysis and Model Validation}

The validation process consists in the comparison of several computational studies with corresponding laboratory ones. The situations here focused are related to a variety of ideal and non-ideal supply voltage conditions as given by Table I. Other conditions have been tested but they were not included in this paper. This is the case of harmonic distortion, transients and voltage flicker.

TABLE I. - Studied Cases

\begin{tabular}{l|l}
\hline \multicolumn{1}{c|}{ CASE } & \multicolumn{1}{c}{ CHARACTERISTICS } \\
\hline 1 - Rated and ideal condition & $127 \mathrm{~V}, 60 \mathrm{~Hz}$ \\
\hline 2 - Voltage interruption & Event duration of 7 cycles \\
\hline 3 - Voltage dip & $\begin{array}{l}\text { Voltage reduction to } 60 \% \\
\text { with } 10 \text { cycles }\end{array}$ \\
\hline 4 - Voltage swell & $\begin{array}{l}\text { Voltage increase to120 \% } \\
\text { with } 10 \text { cycles }\end{array}$ \\
\hline
\end{tabular}

The laboratory arrangement is given in Fig. 5. It comprises a programmable HP6834A source, threephase, $4.5 \mathrm{kVA}$ and other equipment to store the voltage and current waveforms.

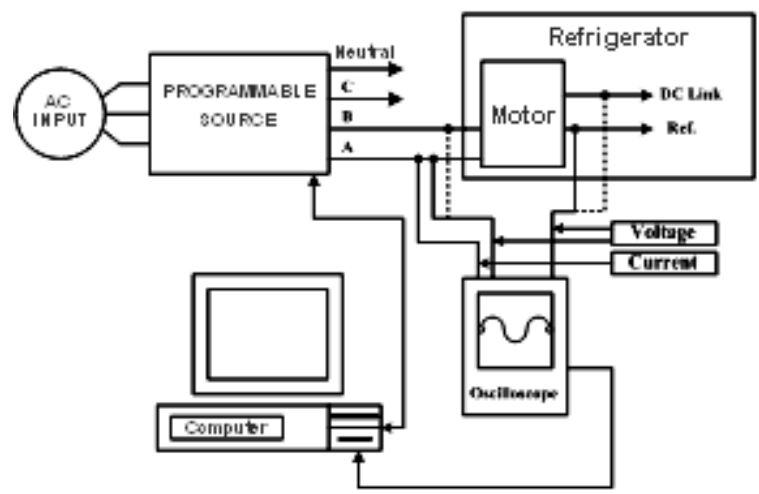

Fig. 5 - Experimental arrangement for the studies.

For each situation, the refrigerator input voltage and current were considered for the performance analysis and validation procedure.

\section{A. Ideal Condition : Case 1}

This first situation considers that the refrigerator is operating with ideal and rated conditions. Thus, this study aims at reproducing the reference case to be used for comparison purposes with other investigations. In addition, the results are used to validate the model as their expected values are previously known from the manufacturer datasheet.
Fig. 6 (a) and (b) illustrate the voltage and current waveforms at the equipment input. As already stated, both computational and experimental results are given. The input voltage is given in blue and the current in red. This standard will be followed for the other results.

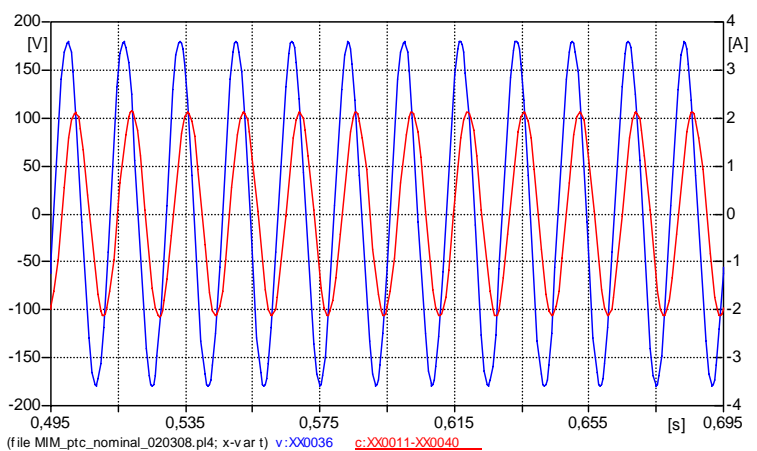

(a) Computational results

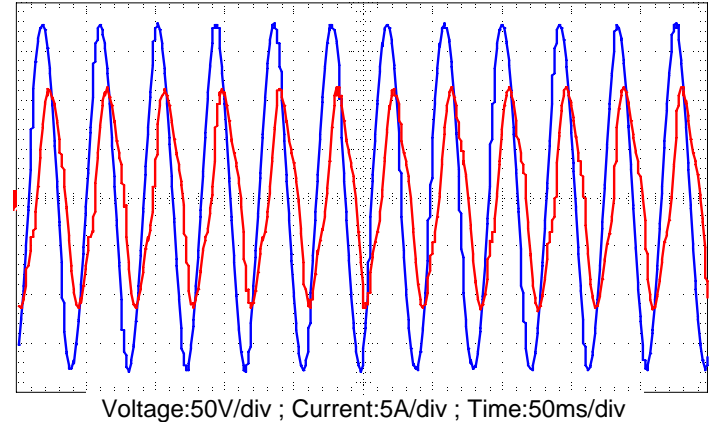

(b) Experimental results

Fig. 6. Input voltage and current - Case 1 - Ideal condition

The RMS and peak value for the input current are given in Table II. Therefore, concerning ideal and rated conditions, the model performance is in accordance with the expected values.

TABLE II. - Computational and Experimental Values

\begin{tabular}{c|c|c}
\hline Input Current & Computational & Experimental \\
\hline RMS (A) & 1,51 & 1,50 \\
\hline Peak value (A) & 2,13 & 2,20 \\
\hline
\end{tabular}

It must pointed out that a small difference between the current waveforms can be readily noticed. This can be justified by the fact that the motor magnetic material saturation was not taken into account. This fact determines that the experimental results have a $3^{\text {rd }}$ harmonic $(180 \mathrm{~Hz})$ that has not been found in computational results.

\section{B. Voltage Interruption : Case 2}

Fig. 7 (a) and (b) show the refrigerator computational and experimental waveforms related to the supply voltage and the input current, when a voltage interruption of 7 cycles occurs. 


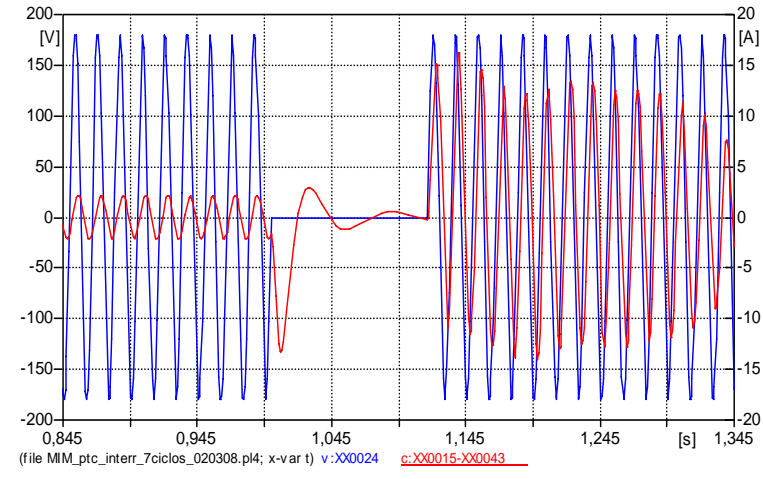

(a) Computational results

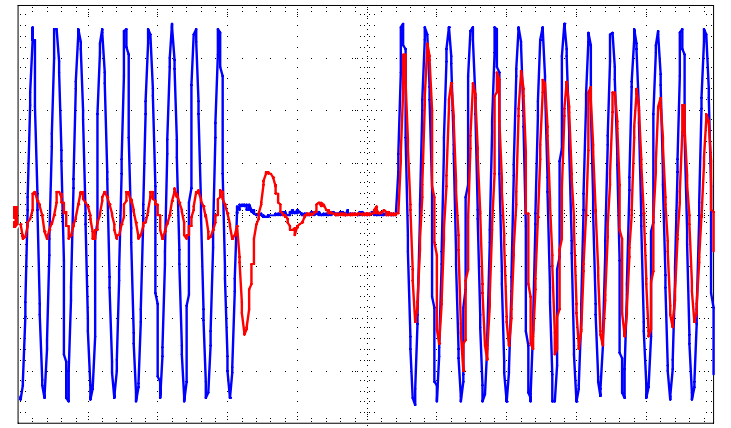

Voltage:50V/div ; Current:5A/div ; Time:50ms/div

(b) Experimental results

Fig. 7. Input voltage and current - Case 2 - voltage interruption.

Table III summarizes the highest peak current at the equipment input after the voltage is recovered.

TABLE III. - Computational and Experimental Values

\begin{tabular}{c|c|c}
\hline Input Current & Computational & Experimental \\
\hline Peak value (A) & 16,31 & 16,40 \\
\hline
\end{tabular}

The waveforms reveal that when the equipment reestablishes the rated voltage, the appliance shows a transient peak current of approximately eight times its rated value. In addition, the general behaviour for the current is in very close agreement. Again, this is a evidence that the proposed model has demonstrated good accuracy.

\section{Voltage Dip: Case 3}

The Fig. 8 (a) and (b) give the voltage and current waveforms at the equipment input when a voltage dip phenomenon is applied during 10 cycles.

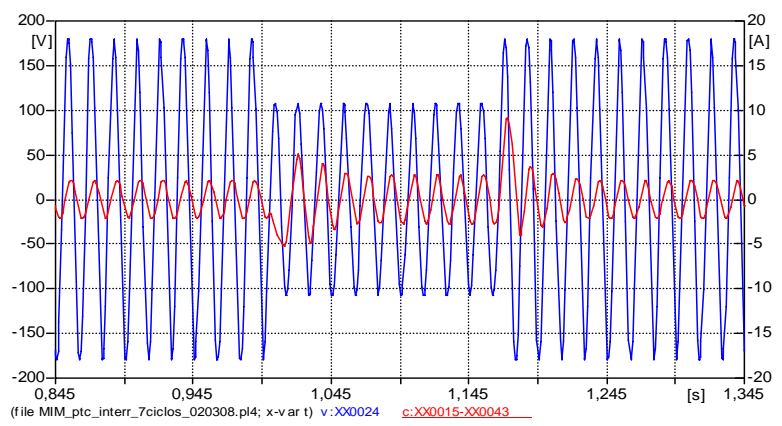

(a) Computational results

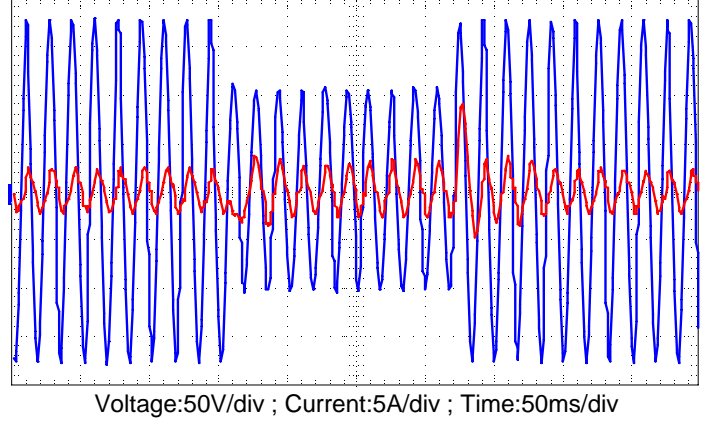

(b) Experimental results

Fig. 8. Input voltage and current - Case 3 - voltage dip.

These figures show that the highest peak found at the current waveform happens immediately after the voltage is restored to its original value. Table IV shows both the computational and experimental peak values.

TABLE IV. - Computational and Experimental Values

\begin{tabular}{c|c|c}
\hline Input Current & Computational & Experimental \\
\hline Peak value (A) & 9,17 & 9,20 \\
\hline
\end{tabular}

\section{Voltage Swell: Case 2}

The Fig. 9 (a) and (b) illustrate the voltage and current waveforms at the equipment input considering both the computational and experimental results. The disturbance is now linked to the so called voltage swell that lasts for 10 cycles.

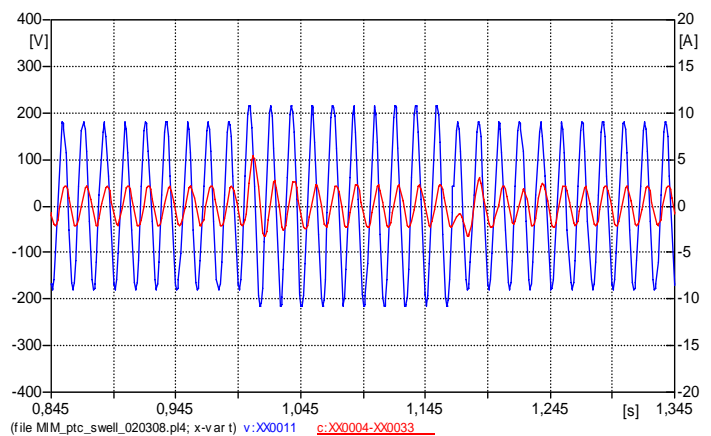

(a) Computational results

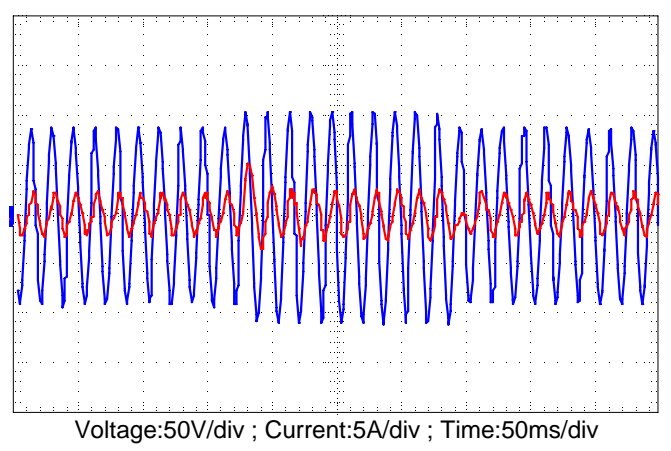

(b) Experimental results

Fig. 9. Input voltage and current - Case 4 - voltage swell. 
The above non ideal situation has produced an increase of the initial values for the input current. The greatest peak value has gone up to nearly twice the rated value. Both the computational and experiment performances are again in close agreement as far as values and waveforms are concerned. Table $\mathrm{V}$ shows the peak values for the currents.

TABLE V. - Computational and Experimental Values

\begin{tabular}{c|c|c}
\hline Input Current & Computational & Experimental \\
\hline Peak value (A) & 5,35 & 5,20 \\
\hline
\end{tabular}

\section{Conclusion}

This paper has proposed a model to handle with commercial refrigerators through time techniques and subsequent implementation in the ATP simulator. The representation finds applications in investigating equipment performance with disturbances occurring on the supply voltage. This matches the requirements associated to a more comprehensive research field seeking for computational means destined to subsidise the analysis and final position about refunding request for damages in household appliances.

The main contribution of this work, in addition to the proposal of the mathematical model and its insertion in the ATP by means of the MODELS routine, is the validation of the developments. So, different computational studies were carried out using ideal and non-ideal supply conditions to the household product here focused. By comparing the theoretical and experimental results it was found that the general behavior achieved with rated and disturbed conditions are in very close agreement. This allows for stating that the model was found appropriated to the targets of studying equipments subjected to typical distribution occurrences and the impacts upon refrigerators and other products that were not considered for this paper proposal.

\section{References}

[1] M. H. J. BOLLEN, Understanding Power Quality Problems: Voltage Sags and Interruptions, USA: Wiley - IEEE Press, 2000.

[2] R. C. DUGAN, M. F. MCGRANAGHAN, H. W. BEATY, Electrical Power Systems Quality, 2nd Edition, USA: McGraw-Hill, 2003.
[3] M. D. Teixeira, R. L. Araújo, L. M. Ardjomand, , A. R. Aoki, N. S. R. Quoirin, I. Wunderlich, “Acceptable Power Quality Limits to Avoid Damages in Appliances", WSEAS Trans. on Circuits and Systems, Vol. 4, May 2005.

[4] A. S. JUCÁ, “Avaliação do Relacionamento entre Consumidores e Concessionárias na Solução de Conflitos por Danos Elétricos: Proposta de Adequação”, Tese de Doutorado em Engenharia Elétrica, Escola Politécnica da Universidade de São Paulo, USP, São Paulo/SP, 2003.

[5] M. D. TEIXEIRA, R. L. ARAÚJO, L. M. ARDJOMAND, , A. R. AOKI, N. S. R. QUOIRIN, I. WUNDERLICH, "Acceptable Power Quality Limits to Avoid Damages in Appliances", WSEAS Transactions on Circuits and Systems, Issue 5, vol. 4, May 2005.

[6] AZEVEDO, A. C., "Desempenho de Refrigeradores Domésticos no Contexto da Qualidade da Energia Elétrica”, Dissertação de Mestrado, Universidade Federal de Uberlândia, julho de 2003.

[7] TAVARES C. E., MENDONÇA M. V. B., OLIVEIRA J. C., DELAIBA A. C., SILVA R. M. T. Aplicativo Computacional para Subsidiar a Análise Técnica de Pedidos de Ressarcimento. CBQEE 2007, Santos SP, 2007.

[8] CARMEIS, D. W., "Os efeitos da Diversidade de Tensões de Distribuição no Setor Elétrico Brasileiro. Estudo do Caso do Refrigerador Doméstico”, Dissertação de Mestrado, Universidade Estadual de Campinas, Campinas-SP, 2002.

[9] Manuais da Empresa Tecumseh do Brasil, São Carlos - SP, disponível em: www.tecumseh.com.br.

[10] DEL TORO. V.,” Fundamentos de Máquinas Elétricas”, USA: LTC - Livros Técnicos e Científicos, 1999.

[11] PACHECO, A. L. S., "Desenvolvimento de Sistemas para Medir a Resistência de Enrolamento em Motores de Compressores Energizados”, Dissertação de Mestrado, Universidade Federal de Santa Catarina, Florianópolis-SC, 2007.

[12] CASTILlO, B. C., AZEVEDO. A. C., OliveirA, J. C., DELAIBA, A. C. "Desempenho de Refrigeradores Domésticos e Condicionadores de $\mathrm{Ar}$ no Contexto da Qualidade da Energia Elétrica”, VSBQEE, Aracaju-SE, Agosto de 2003;

[13] F. L. Alvarado, C. A. Cinizares, A. Keyhani, B. Coates, "Instructional use of Declarative Languages for the Study of Machine Transients”, IEEE Trans. on Power Systems, Vol. 6, No.1, February 1991. 